\title{
Audit of Cord Prolapse Management at King Abdulaziz University Hospital
}

\author{
Anas M. Al Marzouki, FRCSC and Amal S. El Shobokshi, MD \\ Department of OBS/GYN, Faculty of Medicine, Jeddah, Saudi Arabia \\ aalmarzouki@kau.edu.sa
}

\begin{abstract}
To assess the incidence of risk factors, management and outcome of umbilical cord prolapsed in a university hospital setting. A retrospective chart review of women who had cord prolapsed at King Abdulaziz University Hospital over a period of eight years. During the study period there were 49 cases of cord prolapsed $(0.15 \%$ incidence), which includes seven cases of cord presentation. The mean maternal age was 30.31 years. The majority was booked cases $(71.4 \%)$ and 5 were less than gravida (73.5\%). In $10.2 \%$ labor was induced. The incidence of abnormal fetal presentation was $16 \%$, and in six patients the onset of labor was before 31 weeks. The mean diagnosis to delivery interval was approximately 23 minutes; with the exception of two vaginal deliveries and one ventouse delivery, all women underwent crash cesarean delivery. There were 11 admissions to the NICU/SCBU and four mortalities, giving an overall perinatal mortality of $8.15 \%$. In two of the mortality cases there were potentially avoidable factors; the remaining ones were extremely premature babies. Cord prolapsed is still a serious obstetric emergency. The diagnosis to delivery interval is a crucial factor in the management of cord prolapsed. All obstetric units should maintain continuous drills on crash cesarean deliveries.
\end{abstract}

Keywords: Cord prolapsed, Cesarean section, Perinatal mortality, Perinatal morbidity

\section{Introduction}

Cord prolapsed is one of the most serious obstetric emergencies. It is associated with a high rate of perinatal mortality and morbidity.

$\overline{\text { Correspondence } \& \text { reprint request to: }}$

Dr. Amal S. El Shobokshi

P.O. Box 80215, Jeddah 21589 Saudi Arabia

Accepted for publication: 18 May 2009. Received: 17 September 2008. 
Successful outcome depends on several maternal and fetal factors. However, one of the crucial factors is the time elapsed between the incident of the cord prolapsed and delivery.

The primary objective of this study is to audit the management protocol of cord prolapsed in our unit through analysis of the maternal and perinatal outcome of cases diagnosed over a period of eight years. A secondary objective was to assess the obstetric risk factors that could be associated with cord prolapsed.

\section{Patients and Methods}

This study is a retrospective analysis of cases diagnosed as having cord prolapsed at King Abdulaziz University Hospital (KAUH) during the period of January 2000 to the end of December 2007. KAUH is the main teaching hospital in the Western Region of Saudi Arabia. Excluding emergencies, only booked obstetric cases are admitted.

The labor and delivery unit registry for the study period was examined. All cases of cord prolapsed were identified, and the medical records were retrieved. In each case, the following variables were examined: maternal age, parity, gestational age at presentation, obstetric complications/interventions, and method of delivery. In addition, the interval elapsed between the diagnoses of cord prolapsed, "diagnosis to delivery interval (DDI)", variables related to the fetal outcome including weight at birth, and APGAR score; admission and stay in the Neonatal Intensive Care Unit (NICU) or the Special Care Baby Unit (SCBU) until discharge and/or death were analyzed.

All data were analyzed using Statistical Package for Social Sciences (SPSS) V13 on an IBM compatible personal computer.

\section{Results}

During the study period, 32,082 deliveries have been recorded. Of those, there were 49 cases diagnosed as having cord prolapsed, giving an incidence of $0.15 \%$. The mean maternal age was $30.31( \pm 6.49)$ years. The majority (71.4\%) of cases were booked. Regarding parity, $77.6 \%$ of the patients were less than gravid 5 parity in the studied group.

Only $5(10.2 \%)$ cases that labor was induced, while the rest were spontaneous labor. Regarding fetal presentation, there were 5 (10.2\%) 
breech, $3(6.1 \%)$ shoulder presentations, and the rest being vertex presentations. This makes a total of $8(16.3 \%)$ cases where cord prolapsed is associated with mal-presentation.

In $40(81.6 \%)$ cases, the deliveries were after full term pregnancies, whereas the rest had been preterm deliveries; including 2 cases that delivered at 36 wks, 1 case at 31 wks, and 5 cases which delivered extremely preterm between 24-28 wks of gestations.

The mode of delivery was by crash cesarean section in 46 cases, 2 were spontaneous vaginal deliveries and one was delivered by ventouse.

\section{Diagnosis to Delivery Interval (DDI)}

The interval from diagnosis of cord prolapsed to delivery of the fetus was recorded in all cases; the mean duration was 22.78 min.(median $20 \mathrm{~min}$, minimum $10 \mathrm{~min}$, and maximum $47 \mathrm{~min}$.). In the majority of cases, the diagnosis to delivery interval (DDI) was within 20-23 min., while in only four cases it was more than $30 \mathrm{~min}$. Analysis of those cases revealed the following: In one case (DDI $47 \mathrm{~min}$ ) the diagnosis was a cord presentation with good fetal monitoring, another two cases with cord presentation had IDD $45 \mathrm{~min}$ and $35 \mathrm{~min}$, respectively; were frank and footling breech presentations, and both babies were delivered in good condition. In the case with footling breech, the mother had full stomach and spinal anesthesia was used during surgery. In the fourth case with IDD of $40 \mathrm{~min}$ no clear explanation could be found for the delay in undertaking the delivery.

If these four cases are excluded, the mean IDD will be approximately $20 \mathrm{~min}(\mathrm{SD} \pm 7 \mathrm{~min}$, minimum $10 \mathrm{~min}$, and maximum 30 $\min )$.

\section{Mortality and Morbidity}

There were 9 admissions to NICU, 4 of which expired, giving a prenatal mortality of $8.1 \%$. The details of those cases are as follows:

A 26 wks baby, birth weight 970 grams, with APGAR score of 5 at both one and ten min. DDI was $30 \mathrm{~min}$. The exact cause(s) of their death is not known, but most probably due to complications of extreme prematurity. 
A 30 wks gestation twins pregnancy, birth weights 681 and 843 grams (cord prolapse occurred with the $2^{\text {nd }}$ twin). Both were admitted to NICU, and both expired. DDI was $30 \mathrm{~min}$.

The $3^{\text {rd }}$ case was an un-booked, term pregnancy, with cord prolapsed diagnosed in the emergency room, with unknown period of time since rupture of membranes. A baby girl, birth weight 1956 grams, was delivered. APGAR score was zero and one, at one and five min. Resuscitation was done for $25 \mathrm{~min}$. and the baby was admitted to NICU, but expired shortly.

The $4^{\text {th }}$ case was also a term pregnancy, which was in labor and a delay of $15 \mathrm{~min}$. before induction of anesthesia could be performed as the patient had to be shifted to the main operating theater rather than the Labor and delivery suit operating theater. A baby girl weighing 3480 grams, APGAR 1, 5 and 6 at 1,5 and 10 min., respectively. She was admitted to NICU were she expired after 11 days due to severe asphyxia.

There were three cases of neonatal morbidity.

The first one was a term gestation had the diagnosis of cord prolapsed made during labor and delivered by crash cesarean (DDI 12 min). A baby boy weighing 2930 grams with Apgar score of 1, 4 and 5 at 1, 5 and 10 min., respectively, were delivered. The baby was admitted to NICU and was diagnosed later as a case of decorticate brain death.

The $2^{\text {nd }}$ case is a 27 wks gestation, which was delivered by crash cesarean (DDI $24 \mathrm{~min}$ ). A baby girl weighing 970 grams was delivered with Apgar score of 2 and 5 at 1 and $5 \mathrm{~min}$. She was admitted to NICU due to prematurity. She was discharged home 8 wks later.

The last case is a term pregnancy, diagnosed as cord prolapsed while in the L\&D unit. She was delivered by a crash cesarean (DDI 10 min). A baby girl weighing $2915 \mathrm{~g}$ was delivered with Apgar score of 0, 2 and 9 at 1,5 and $10 \mathrm{~min}$. She was admitted to the NICU and was discharged home 11 days later.

\section{Discussion}

Cord prolapsed is an emergency obstetric complication that is difficult to predict. In the present study the incidence of cord prolapsed was $0.15 \%$ which is generally agreeable with similar studies published from other tertiary referral centers ${ }^{[1-4]}$. This, however, does not reflect its 
true community based incidence which may be higher, especially in societies when a large proportion of its deliveries take place outside health care facilities. Traditionally, factors such as prematurity, unstable lie, grand-multiparity, induction of labor, have been implicated as predisposing factors. In the present study fetal lie was abnormal in about $16.3 \%$ of cases and about $18.4 \%$ were premature births. Although, those as well as other factors, such as grand-multiparity and polyhydramnios are recognized risk factors for cord prolapsed, its sensitivity, in any single case is too low to be predictive for cord prolapsed.

It is possible that in such high risk cases, the use of ultrasound to search for cord presentation reduces the emergency encounter of cord prolapsed; hence the potential complications of crash cesarean can be reduced. Some studies have examined the overall role of antenatal ultrasound diagnosis in the management of cord presentation ${ }^{[5-6]}$. In prospective follow-up of cases diagnosed as having cord presentation, it was possible to avoid crash cesarean in a large proportion of cases that showed persistent cord presentation. However, the authors' emphasis that a repeat scan, including intrapartum one, should be performed whenever an antenatal diagnosis of cord presentation is made; since in a large proportion of such cases the condition will be spontaneously resolved ${ }^{[5,6]}$.

In clinical practice the crucial factor for successful rescue of fetuses with cord prolapsed depends on the duration of the DDI. Indeed, one of the parameters for evaluating the standard of Obstetric practice is the time required to undertake an emergency cesarean ${ }^{[2,3,7,8]}$. According to international bodies, the time required to perform an emergency cesarean should not exceed $30 \mathrm{~min}$. However, the term "Crash" cesarean refers to even shorter periods of time. In the present study, the mean interval from DDI was about $20 \mathrm{~min}$, which is well within the recommended range, and is compatible with that reported in similar reviews on the management of cord prolapsed.

While shortening of the DDI is a crucial factor in determining the outcome of management of cases of cord prolapsed, every effort should be made to reduce cord compression and fetal hypoxia during those few minutes. The Vago method of rapid instillation of saline into the bladder has been described to relieve cord pressure during preparation for cesarean $^{[9,10]}$. Caspi et al. described no fetal deaths occurring in the 88 
case managed by bladder instillation and CS in spite of long diagnosis to delivery intervals ${ }^{[9]}$. In our unit this technique has not been applied. Instead, once cord prolapsed is diagnosed, the instruction is to immediately ensure that it is replaced within the vagina and decompression of the cord is maintained manually by elevating the presenting part, until the patient is on the operating table and a skin incision is made. It is almost impossible to answer in an evidence based fashion the question of which maneuver is more effective as a management tool.

In the present study, the perinatal mortality was $8.1 \%$. At least two were avoidable mortalities. In a term fetus, there was a delay of more than $15 \mathrm{~min}$ in induction of anesthesia and the baby was asphyxiated at birth and died at a later date in the NICU. The second case was a laboring woman who apparently had cord prolapsed for an unknown period of time before the diagnosis was made and an immediate cesarean delivery was undertaken. The third term infant was a patient who presented to the emergency room with cord prolapsed, and despite a crash cesarean the baby was born flat. The remaining mortalities and NICU admissions were cases of cord prolapsed compounded with extreme prematurity.

Finally, it is of interest that the incidence of cord prolapsed is very low despite the widespread prevalence of its associated risk factors. It is possible to hypothise that prolapsed of the cord has multi-factorial basis. It could be attributed to intrinsic defect in the "tone" of the cord or its collagenous components. Other mechanical factors such as its length, or relation to the lower segment could also play a role. The validity of such hypotheses requires large multi-center studies that include large numbers of cases of cord prolapsed.

In conclusion, in the present study the incidence of cord prolapsed as well as the perinatal mortality and morbidity are comparable to those reported in the literature. However, some of the serious morbidity and mortality cases could have been avoided. The importance of continuous drills on crash cesareans in reducing the DDI cannot be overemphasized. It ensures the obstetric team that including medical, nursing and ancillary staff are well aware of procedures to be undertaken in emergency situation. A yearly audit should be undertaken. Further studies are needed to examine the role of antenatal ultrasound diagnosis of cord presentation 
in reducing the rate of crash cesareans, and the effectiveness of techniques such as the Vago method in the management of cord prolapsed.

\section{References}

[1] Ylä-Outinen A, Heinonen PK, Tuimala R. Predisposing and risk factors of umbilical cord prolapse. Acta Obstet Gynecol Scand 1985; 64(7): 567-570.

[2] Uygur D, Kiş S, Tuncer R, Ozcan FS, Erkaya S. Risk factors and infant outcomes associated with umbilical cord prolapse. Int J Gynaecol Obstet 2002; 78(2): 1270-130.

[3] Murphy DJ, MacKenzie IZ. The mortality and morbidity associated with umbilical cord prolapse. Br J Obstet Gynaecol 1995; 102(10): 826-830.

[4] Critchlow CW, Leet TL, Benedetti TJ, Daling JR. Risk factors and infant outcomes associated with umbilical cord prolapse: a population-based case-control study among births in Washington State. Am J Obstet Gynecol 1994; 170(2): 613-618.

[5] Lange IR, Manning FA, Morrison I, Chamberlain PF, Harman CR. Cord prolapse: is antenatal diagnosis possible? Am J Obstet Gynecol 1985; 151(8): 1083-1085.

[6] Raga F, Osborne N, Ballester MJ, Bonilla-Musoles, F. Color flow Doppler: a useful instrument in the diagnosis of funic presentation. J Natl Med Assoc 1996; 88(2): 94-96.

[7] Prabulos AM, Philipson EH. Umbilical cord prolapsed: Is the time from diagnosis to delivery critical? J Reprod Med 1998; 43(2): 129-132.

[8] Nizard J, Cromi A, Molendijk H, Arabin B. Neonatal outcome following prolonged umbilical cord prolapse in preterm premature rupture of membranes, BJOG 2005; 112(6): 833-836.

[9] Caspi E, Lotan Y, Schreyer P. Prolapse of the cord: reduction of perinatal mortality by bladder instillation and cesarean section. Isr J Med Sci 1983; 19(6): 541-545.

[10] Katz Z, Shoham Z, Lancet M, Blickstein I, Mogilner BM, Zalel Y. Management of labor with umbilical cord prolapse: a 5-year study. Obstet Gynecol 1988; 72(2): 278-281. 


\section{تقييم نظام معالجة حالات نزول الحبل السري في مستشفى جامعة الملك عبد العزبز}

\section{أنس محمد المرزوقي، و أمل صالح شبكثي}

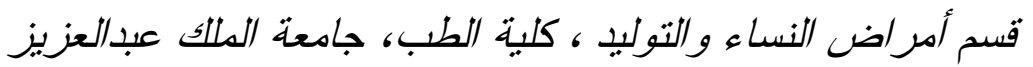

جلة ، المعلكة العربية السعودية

المستخلص. يهدف هذا البحث إلى دراسة نسبة حدوث نزول الحبل السري، وعوامل الخطر المؤدية لها، وطرق معالجتها، والنتائج

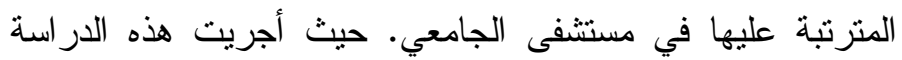

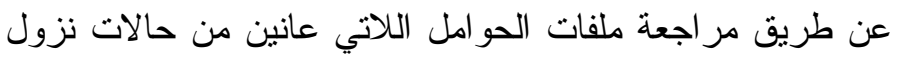

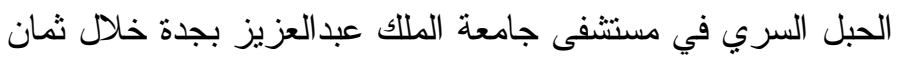

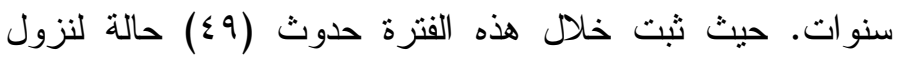

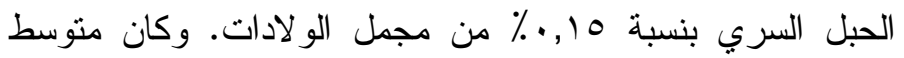

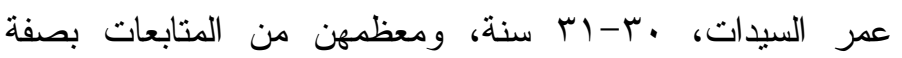

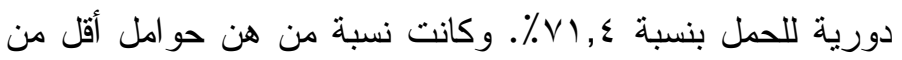

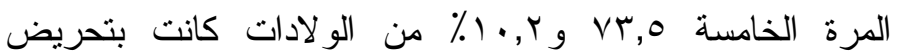

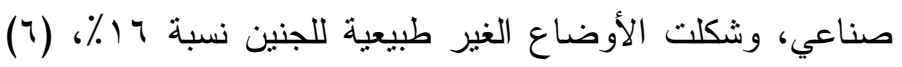

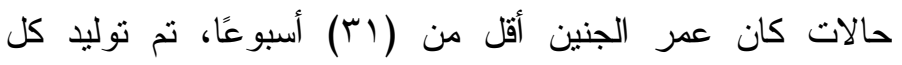

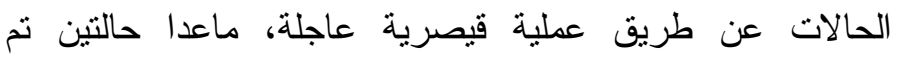

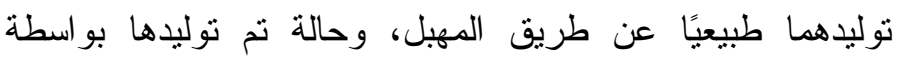

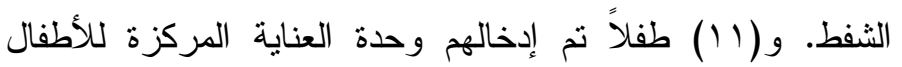

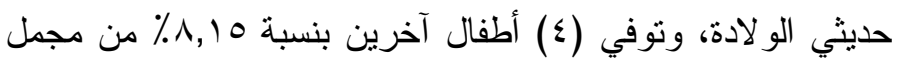

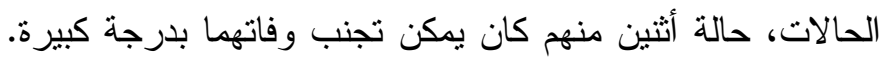

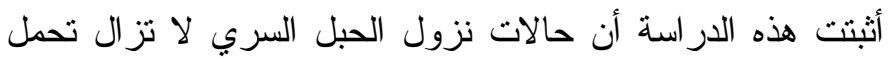

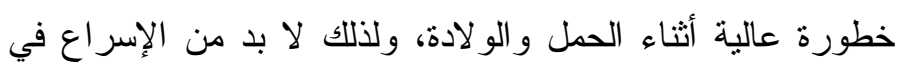
التوليد الجر احي بعملية قيصرية. 